\title{
The Instant Glamour of Mobile Phone Cameras
}

\author{
Yang Jing ${ }^{1}$ Luo ZheHui ${ }^{2}$ \\ ${ }^{1}$ School of Design, South China University of Technology \\ ${ }^{2}$ School of Fine art,South China Agricultural University
}

\begin{abstract}
:
With the continuous development of the high-pixel mobile phone market, the superiority of the mobile phone's ability to quickly and easily capture images has resulted in them becoming integrated into the lives of the general public. The popularity of mobile phone photography enables users to instantly capture, express, and share life's most compelling moments. The camera phone's charm of instant expression is not limited to records and memories, it's also a kind of emotional expression and a way to release of one's innermost feelings. With only a mobile phone which can take pictures, keen observation and a love of life, everyone can become an artist of life.
\end{abstract}

Keywords: Mobile phone photography, instant glamour

On June 11 1997, entrepreneur Philippe Kahn became the first person to take a picture with a mobile phone camera and post it on the internet. It was a picture of his baby daughter. At the time mobile phones did not have color screens, nor a camera, so he combined a mobile phone with a digital camera, creating a prototype to complete the shooting. The digital camera was responsible for taking the pictures, and data was transferred via a connection to the phone, which in turn transferred it in real-time to the Internet. Philippe Kahn had created the precedent for mobile phone photography, and along with the major mobile phone manufacturers began to develop a true mobile phone camera. Today, high-pixel mobile phones have become a regular phenomenon. Using a mobile phone to take photos and share on the Internet has become commonplace; you can often see couples on the street snapping pictures using the self-timing camera on their phone, or pleasantly surprised parents capturing images of their children growing up. Additionally, mobile internet is constantly becoming faster, accelerating the speed at which people can post to the Internet. Mobile phones permeate each and every aspect of society and have become integrated into the lives of the general public, to a large extent changing our way of life and altering our consciousness; mobile phones have ushered in a new cultural phenomenon.

\section{The Instant Glamour of Mobile Phone Cameras}

The camera phone's glamour lies in it's ability to take pictures from a first-person point of view, expressing the photographer's momentary thoughts and feelings, as well as being able to show the photographer's rich three dimensional life on an ordinary flat plane. The photographer can immediately take pictures which reflect both social life and natural phenomena, showing the photographer's own perspective of the world. Additionally, it conveys the photographer's thoughts, feelings, 
observations and understanding of life. In spite of the phone camera's vast improvements in pixel density, there is still a large gap between phone cameras and professional cameras, for example, in terms of color, image quality and exposure. Nevertheless, the phone's camera lives up to immediate needs of fast-paced life: high pixel density and complex features are not necessary to capture the people and things in life. Differing from the traditional camera, the phone camera seeks convenience; a means of recording life.

Compared with the traditional camera, mobile phone photography has many advantages in terms of convenience. First of all, a typical traditional camera is usually around 1 kilogram in weight, whereas a normal mobile phone is between 100 to 200 grams. In contrast to traditional cameras, the mobile phone is light and handy, offering casual freedom. The phone camera is fast and convenient, saving the photographer from the trouble of dealing with the complex procedures of professional cameras, nor is there any cumbersome tripod or film to deal with. Using a phone camera is as simple as lifting it out of your pocket and casually taking pictures of the things you like. Secondly, after you've taken pictures with a traditional camera, you need to connect it to a computer to export the images for display, processing and transmission. Whereas images from the mobile phone camera are ready immediately. With the images on your mobile phone, you can use the image editing software on your phone to process your images at any time, and instantly share with your friends and family via the Internet using media platforms. It's both convenient and efficient. On September 25, 2009, the world's first iPhone picture album "The Best Camera Is The One That's With You" was published. On the USA's Amazon website, first day sales broke all records for photography books. This book is international commercial photography's great master Chase Jarvis' visual diary using a mobile phone camera. As a professional photographer, Chase considers the best camera to be the one that you carry with you. It's clear that the mobile phone camera is increasingly replacing the traditional heavy camera. It is a viable alternative for both professional photographers and hobbyists alike in the quest of taking beautiful pictures.

In the past, people thought of photography as an expensive pleasure. In the age of film, people bought high-cost photographic equipment, and also needed to continuously buy film, to the extent that only a small number of people were able to take up photography. Nowadays, the popularity of mobile phone photography allows every mobile phone user to capture, express, and share life's special moments. Without the high barrier to entry of professional cameras, no matter whether you are a novice or professional, you only need to have a camera enabled mobile phone, keen observation and a love of life to become an artist of life.

\section{The Instant Glamour of Mobile Phone Cameras}

\subsection{The Glamour of instant capture}

Internet technology is developing at lightening pace, information is received from diverse sources and connection speeds are always increasing. At the same time, people are able to appreciate the excellent works of famous artists and photographers, and to some extent improve their own aesthetic judgment. From seeing outstanding works from abroad, people are able to increase their understanding of photography, and from salon photography they are able to 
develop a stronger aesthetic sense. The general public use internet platforms to communicate, for mutual learning, and to discover a sense of artistry in each and every scenario of life. They use the phone camera to instantly capture what they see. It's not difficult to see people's increasing thirst for the instant capture of beauty.

The significance of instant capture is far greater than as a means to record life's moments, as opposed to artistry. It's most likely to be a surprising moment you were not prepared for which comes all of a sudden, and without preparation you're able to take some quick snapshots using your phone camera, perfectly preserving the mood and memory of the moment. In 2012 world-famous Chinese designer Alan Chan held an iPhone photography exhibition called "iEye-ai." Most of the picture at the exhibition were about his business or travels, fleeting beauty in which there is not enough time to pull out a camera. He simply used the mobile phone camera to instantly capture things of beauty and affection as seen by the eye. Relentlessly without plan or late modifications, he captured many splendid moments, one by one, using the lightest tool of photography, with each image being faithful to the original moment. It's easy to see that the least planned moment is also the most pure. Phone photography is inadvertently natural, leaving the natural beauty of the moment which is not deliberately controlled. It perfectly captures and preserves a moment which cannot otherwise remain.

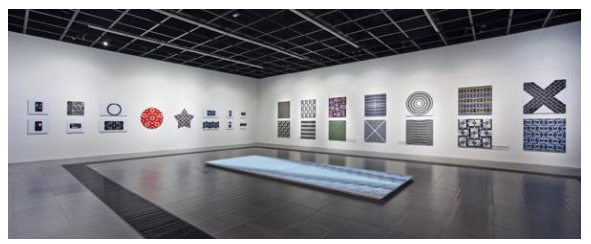

Fig. 1: Alan Chan "iEye-ai" iPhone Photography Exhibition

\subsection{The Glamour of Instant Expression}

The average person can discover beauty, and has the power to create beauty. Compared with painting and music, mobile phone photography is a relatively easy art to master. The glamour of instant expression isn't limited to records of memories, it's also a kind of emotional expression and a way to release one's inner-most feelings. Once, our parents were accustomed to using words to record their lives and express their ideas, but now people prefer to use the fast and convenient phone camera to record their lives and express their views. Photos have visual impact and allow the viewer to feel what the photographer is feeling. A whole family photo expresses family love, pictures of friends show friendship, scenic photos deliver the stunning natural landscapes, and pictures of the departed give us a sense of yearning. Via the photograph's real-time response, the angle of vision, and lighting, the thoughts and emotions of the moment are expressed in a picture. What's more, with the continuous development of mobile phone image processing software, the photographer doesn't need to export the image, as it's possible to edit, beautify, and stylize the image on the phone. Through using this software, it's possible to apply rendering effects to make the photo more rich in beauty. Mobile phone image processing software is a lot more simplified than professional computer image editing software, no complex professional knowledge is needed to use it, allowing average users to easily realize the expression of the moment.

Instant expression exercises people's sense of beauty, it also improves many other aspects of their photography, such as level of creativity, composition, color, use of lighting in their pictures and so on. A comprehensive improvement is made to their aesthetic ability. In addition, when a person captures the expression of 
the moment, it cultivates their eye for the exquisite. The world of mobile phone photography makes people pay more attention to life and to the people and things around them.

\subsection{The glamour of instant sharing}

This age of science and technology is of great benefit to mankind, people have more channels with which to express their emotions. Media platforms used for sharing pictures are becoming faster and more convenient. Social media platforms such as Instagram, Facebook and Sina Weibo are becoming a big part of people's lives and are the new way for people to communicate. The combination of increased network speed, and the popularity of public wireless networks, facilitates mobile phone users to post their pictures or emotional expressions on media platforms, thus realizing interaction. On Sina Weibo, for instance, you can have conversations with anybody you are interested in, comment on posts, forward posts from other people, and share ideas and stories with your fans. Sharing is indeed the greatest feature of social media platforms. People are keen to post their favorite things on weibo to share with people whom they know and also people they don't know. A picture or a few words, the possibilities are endless: pleasantly surprised parents capturing images of their children growing up; pictures of a mouth-watering feast, the marvelous scenery captured by a person infatuated with travelling; lovers exchanging rings and making an eternal promise..... Instant sharing is like an invisible spiritual bond that closes the distance between people and allows them to share joy, sorrow, frustration and laughter. People enjoy the pleasure of sharing, and in this spiritual home find contentment.

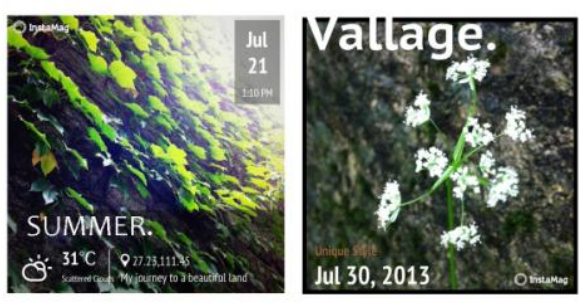

Figure.2:Writer using Sina Weibo

to post travel photos

\section{Conclusion:}

Instant capture, expression, and sharing can be both surprising and moving. Whether it's visually stunning spectacles, transient scenery, or fleeting occurrences, by merely picking up your mobile phone camera you can preserve life's precious memories. The phone camera gives us a pair of eyes for discovering beauty, teaching us to carefully observe life, have a greater love of life, and easily express our feelings. This convenient way of keeping visual records allows people during work, leisure or travel to be able to enjoy the pleasure that the phone camera brings. In the wake of changes brought about by the information age, people have shifted from using words to express themselves to using pictures. There is no doubt that mobile phones have utterly change mankind's rhythm of life and means of communication. The phone camera has become a symbol of contemporary culture and is an expression of modern life.

\section{References:}

[1] Delicate Youth, "Who was the first person to use a phone to take pictures?', Love for life: a history lesson, Love Life Network (Oct, 2011)

[2] Xiang Wei-Dong, Zhang Chu, 'Media Convergence Under the Background of Camera Phones and Mobile Phone Photography', ChongQing Normal 
University Academic Journal, Philosophy and Social Sciences Edition (Oct, 2012)

[3] Hong Kong's famous designer Alan Chan, Using the iPhone to Shoot the Beauty of Life, China News Network (Sept, 2012)

\section{References:}

[1] Yang Li-Li, "From 'Photography Centralized' to 'Social Network Centralized', Center for Compatitive Study of the History of Personal Photography", News Knowledge ,pp. 7986, 2012

[2] Zong Shi, "'Four Modernizations', The Pursuit of Mobile Phone Photography's Road Ahead", China Photography Press,pp. 103-105, 2007
[3] Liu Feng, "An Introduction to Photographic Art", SuZhou University Press ,pp. 20-34,2011

[4] Song Xiao-Gang, "Instagram: Bringing about Photography's New Economy", China Photography Press , 2012 